Consultant posts in psychotherapy appeared separately in DHSS statistics for 1975 for the first time, having previously been included within the figures for Adult Mental Illness. In 1975, ten Consultant Psychotherapist posts (six whole-time equivalents) were recorded, and this figure increased steadily as more post holders declared themselves as specialist psychotherapists, after initial reluctance on the part of many to relinquish the title of Consultant Physician in Psychological Medicine or Consultant Psychiatrist, since the title of Psychotherapist did not assert medical status. By 1984 there were 91 Consultant Psychotherapist posts (61.2 whole-time equivalents), but there was no record of the number of Consultant Psychiatrist post holders with specified contractual Special Responsibility or Special Interest in psychotherapy. Such details are held only by Regional Health Authorities, and are not available for manpower statistics.

The prolonged debate which ensued upon the circulation of the discussion document 'Guidelines for the Training of General Psychiatrists in Psychotherapy' led to much modification of the recommendations before the guidelines were accepted as College policy. ${ }^{1}$ The fear that lack of consultant psychotherapists would make such a proposal impracticable was one reason for the rejection of mandatory training in psychotherapy during the general professional training period.

The Psychotherapy Specialist Section is the largest section in the College, and membership includes trainees, retired and overseas colleagues. It is not possible to identify those who are currently NHS consultants, nor the proportion of all consultant psychiatrists who are members of the Section. It seems likely, however, that most consultants who are interested in psychotherapy, whether behavioural or dynamic, would be members of the Section, particularly if they are involved in the formal provision of a psychotherapy service or teaching.

In the absence of any data about the extent of provision of psychotherapy in the NHS and the numbers of consultant psychiatrists designated as having Special Responsibility or Special Interest in psychotherapy, it was decided to circulate a confidential questionnaire with the Annual Report to all members (approximately 1800) of the Section. Some $\mathbf{5 0 0}$ members responded, including some long retired and many trainees. The information supplied, albeit incomplete, provides for the first time some detail about the availability of psychotherapeutic treatment throughout the country. It also confirms the interest in providing supervision and training for psychotherapy of many consultant psychiatrists who have no specialist designation.

\section{The questionnaire}

A brief and simple form was used to encourage response. Information was sought on age, sex, Regional Health Authority, main place of work and details of title and contract, including number of sessions worked and number of sessions in psychotherapy. If their contracts do not specify psychotherapy, respondents were asked to estimate the approximate sessional time, if any, spent on different types of psychotherapy each week. Information was also sought on supervision and teaching.

\section{Response}

A total of 508 questionnaires were returned prior to coding. (Late responders are not included in this analysis). Those answering YES to any part concerning the practice, supervision or teaching of psychotherapy (350) were coded and analysed by computer using an SPSS-X programme. Those replies not coded (158) included responses from trainees, retired and private practitioners and other grades.

Since the survey was undertaken with the specific aim of identifying consultants practising psychotherapy who are not included in manpower statistics, we were surprised that so many consultant psychotherapists took the trouble to reply. They provided valuable information about their contribution to teaching and supervision.

\section{Analysis of responses}

The questionnaire was returned by 350 consultants currently in practice (sex ratio 3 male: 1 female) and $22 \%$ of the men and $19 \%$ of the women responders were consultant psychotherapists. Only one respondent failed to identify (his) title.

The 350 consultants belonged to three main groups:

Consultant Psychotherapists including designated special interest/responsibility $101 \quad(29 \%)$

Consultant Child \& Adolescent Psychiatrists 67 (19\%) Consultant Psychiatrists/Academic

Appointments

\section{Place of work}

Of the 350 consultant respondents, 313 supplied information about their employing Authority which enabled identification of their regional distribution, and only five respondents failed to give information about main place of work. (See Fig. 1).

$31 \%$ work primarily from a district general hospital base, $38 \%$ from a mental hospital; $15 \%$ were based in a child or family unit, $6 \%$ operated from an out-patient clinic and the 


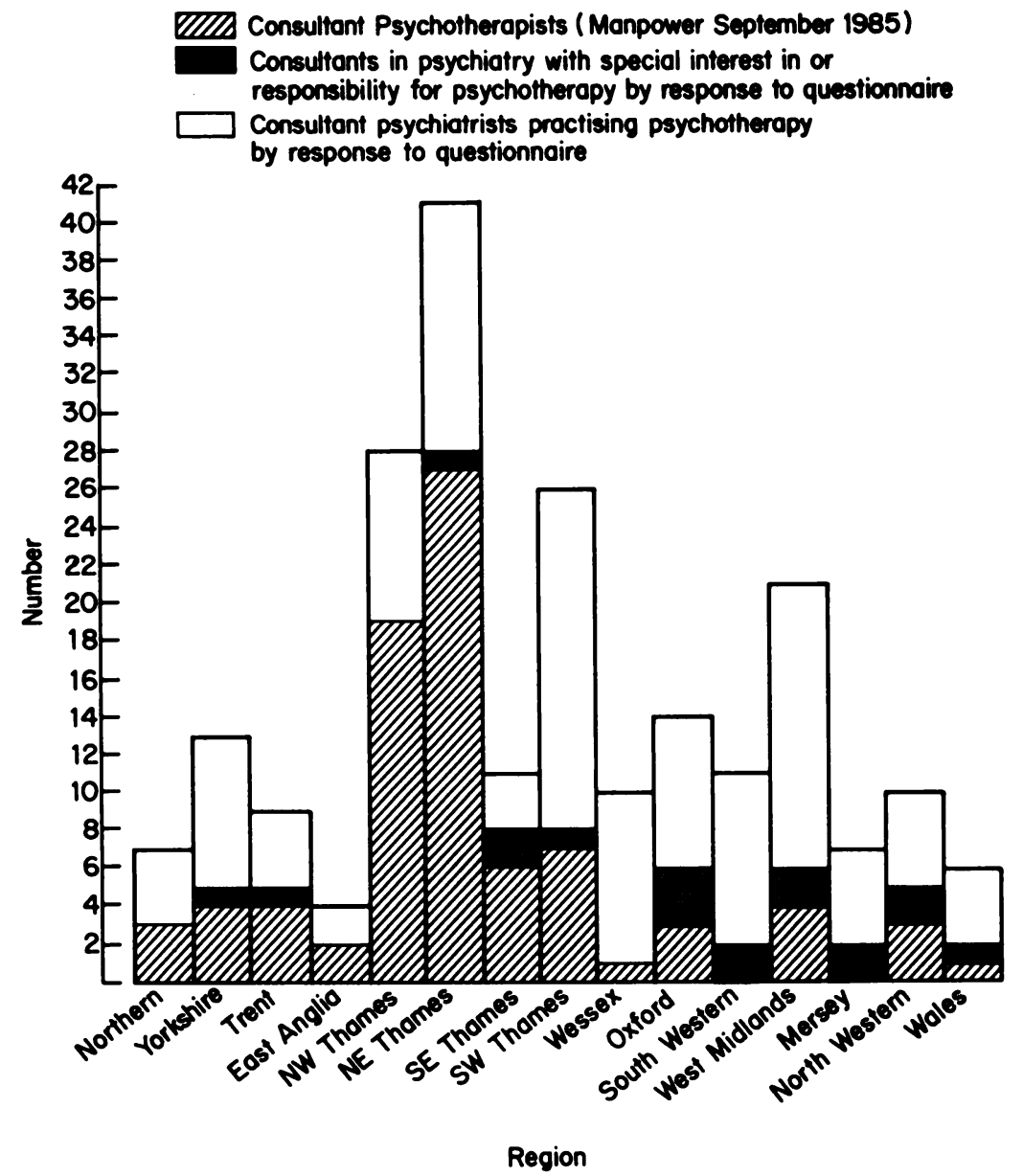

Fig. 1. Number of NHS Consultants by region.

remainder operated from a variety of settings including day units and forensic services.

\section{The psychotherapists}

Three $(1 \%)$ of respondents are Consultants in Behavioural Psychotherapy (one each from SW Thames, Oxford and Trent regions), and their replies have been excluded from the following analysis of psychotherapists' work, to avoid confusion.

Seventy-two Consultant Psychotherapists responded, and in addition 22 Consultant Psychiatrists identified themselves as having Special Responsibility (4) or Special Interest (18) in Psychotherapy. There were a further four replies from Senior Lecturers in Psychotherapy. In all, these 98 consultants work between 2 and 11 sessions (mean: 7 sessions) weekly in psychotherapy.

The 30 psychotherapists based in mental hospitals each worked an average of six sessions/week. The 28 psycho- therapists based in DGH and teaching hospitals worked an average of eight sessions/week each. Eighteen psychotherapists working from an out-patient clinic base also averaged eight sessions weekly.

\section{Supervision}

93\% of psychotherapists supervise psychotherapy, but only $80 \%$ supervise registrars and $57 \%$ supervise senior registrars in this work. Two thirds provide supervision for nurses and social workers; between a quarter and one third supervise general practitioners, occupational therapists and others.

Just over half the respondents provide formal psychotherapy supervision on an individual basis, and more than two thirds provide it in a group. Less than one third supervise group therapy and a similar proportion supervise general case discussion in seminar form. Only one respondent conducts live supervision. 


\section{Teaching}

$85 \%$ of psychotherapists teach psychotherapy; two fifths contribute to the teaching of medical students and nurses. Nearly two thirds use seminars or formal lectures for teaching, but only $15 \%$ felt that they were involved in informal teaching of psychotherapy.

\section{The psychiatrists}

166 Consultant Psychiatrists responded to the survey. Their replies were analysed with the 16 responses from Professors, Readers or Senior Lecturers and other Consultants. The majority of them spent some time each week practising psychotherapy, although it is not designated in their contracts.

These 182 consultants estimated that they spend an average of slightly less than one and a half sessions each per week on psychotherapy of some sort, most of them undertaking two or three types of psychotherapy regularly. Individual psychotherapy is practised by two thirds of them; nearly one third of those practising individual psychotherapy spend one session per week doing so, the remainder doing half a session or two sessions weekly.

Almost one half of the consultant psychiatrists were based in mental hospitals; three quarters of these practised individual psychotherapy, and one third practised group therapy.

Three quarters of the consultant psychiatrists said that they supervise psychotherapy, $60 \%$ of them providing supervision for registrars, and $11 \%$ for general practitioners.

The child and adolescent psychiatrists

Sixty-seven Consultants in Child and Adolescent Psychiatry responded, of whom nearly all practise individual psychotherapy $(90 \%)$ and family therapy $(95 \%)$.

These consultants devoted an average of 3.75 sessions weekly to psychotherapy. Most time was devoted to family therapy, as might be expected, accounting for 2.9 sessions per week on average for those consultants who practise it. Marital therapy and individual psychotherapy each occupied about one session per week of those consultants practising it.

$90 \%$ of the consultants in child and adolescent psychiatry said that they supervise psychotherapy, $65 \%$ supervising registrars and $61 \%$ supervising social workers. Most gave formal supervision to individuals or groups, but $10 \%$ gave live supervision. $67 \%$ said that they taught psychotherapy.

\section{Comment}

The survey has provided useful information, not previously available, about the extent of psychotherapy provision in the NHS by consultants with no psychotherapy designation in their contracts. Whilst the information cannot be regardded as comprehensive, it is interesting to note that those regions which are relatively well endowed with consultant psychotherapists do not appear to have less involvement in psychotherapy by consultant psychiatrists than those regions with fewer consultant psychotherapist posts. (Fig. 1).

It is evident from the response to the questionnaire that consultant psychiatrists are providing some formal psychotherapy to a greater extent than has previously been documented, and that they are providing some supervision opportunities for trainees in each region. This must be some small comfort to trainees working without access to a recognised psychotherapy training scheme, but is no cause for complacency when the number of posts in psychotherapy continues to fall far short of the College recommended norms. ${ }^{2}$ Gross disparities between the regions indicate the need for a sustained initiative to promote the development of consultant psychotherapist posts if even the interim goals are to be achieved in the short term. Otherwise the future development of services in the specialty looks bleak.

\section{ACKNOWLEDGEMENTS}

Jean Wales and Coralie Gill gave valuable assistance in the preparation of the questionnaires and of this report. Mr C. Jennings carried out the computer analysis, which was supported by a grant from the Royal College of Psychiatrists.

'Guidelines for the training of general psychiatrists in psychotherapy. Bulletin of the Royal College of Psychiatrists, October 1986, 10, 286-289.

${ }^{2}$ 'Norms' for Medical staffing of a psychotherapy service for a population of 200,000. Bulletin of the Royal College of Psychiatrists, October 1975, 4-9.

Pamela Ashurst ANNE Nightingale January 1987

\section{Liaison Psychiatry Conference}

The College Group for Liaison Psychiatry will be holding a weekend conference at St Edmund Hall, Oxford from 18-20 September 1987. There will be sessions on the organisation of the liaison service, research methods, somatisation disorders, the management of attempted suicide, the evalu- ation of treatment interventions and work in progress. There will also be a poster session for the presentation of research and clinical developments. Residential fee $\mathbf{£ 6 0 . 0 0}$. Further information can be obtained from Deborah Hart at the College. 